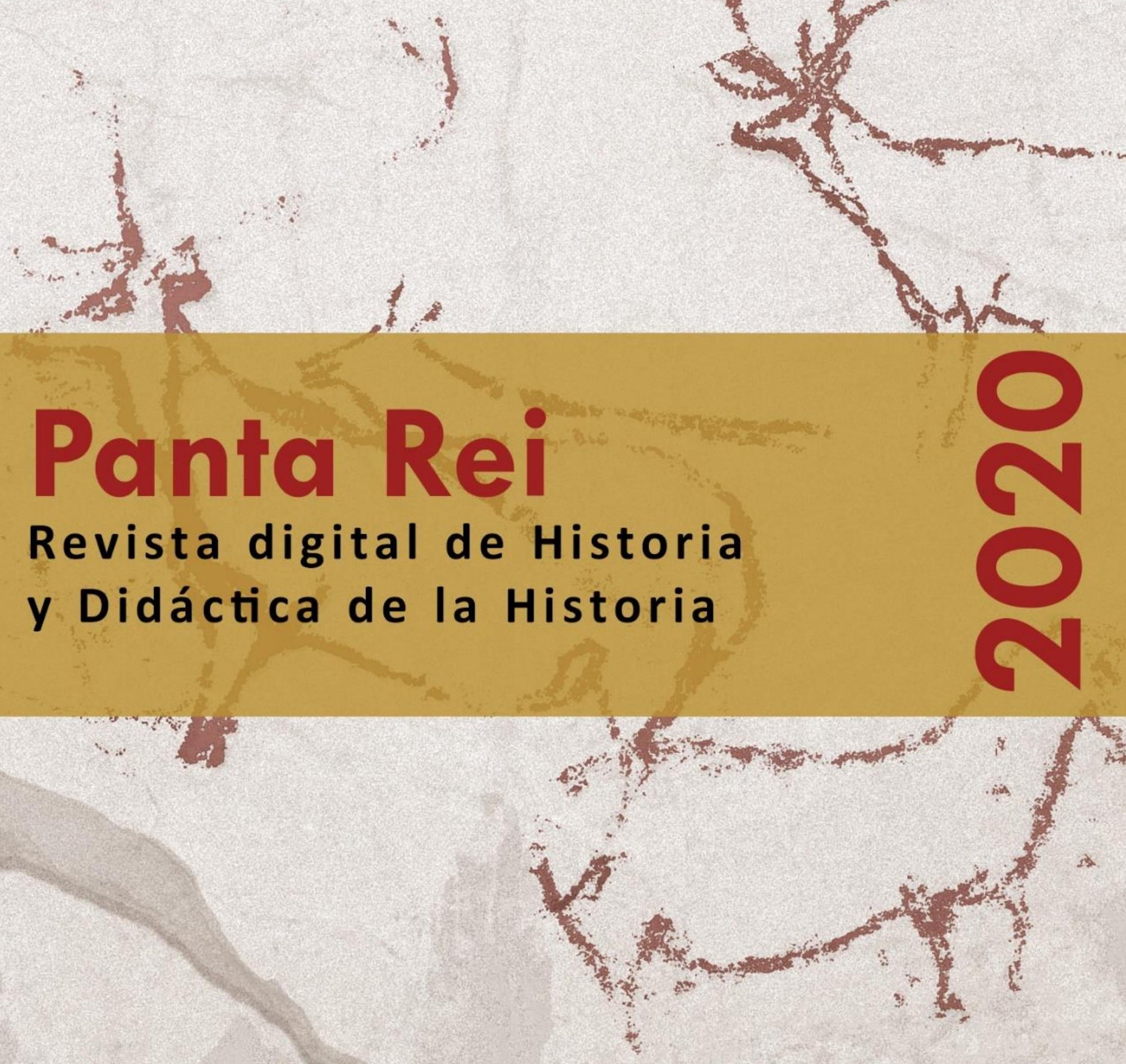




\section{0}

Revista anual

Fecha de inicio: 1995

RevistaPantaRei.pantarei@um.es

\section{Edita:}

Centro de Estudios del Próximo Oriente y la

Antigüedad Tardía - CEPOAT

Edificio Universitario Saavedra Fajardo.

Universidad de Murcia

C/ Actor Isidoro Máiquez, 9

30007 - MURCIA - ESPAÑA

Teléfono: $(+34) 868883890$

cepoat@um.es

Web: www.um.es/cepoat/pantarei

Ediciones de la Universidad de Murcia - EDITUM

Edificio Pleiades. Campus de Espinardo.

Universidad de Murcia

$\mathrm{C} /$ Campus, s/n

30100 - MURCIA - ESPAÑA

Teléfono: $(+34) 868883013$

En portada: calco de las pinturas rupestres de la editum@um.es

Web: https://www.um.es/web/editum/

Cueva del Niño. García Moreno et al., 2016.

Edición 2020

ISSNe: 2386-8864

Responsables de los textos: sus autores.

ISSN: $1136-2464$

Depósito legal: MU-966-1995

Responsable de la presente edición: Consejo Editorial de Panta Rei. 


\section{CONSEJO DE REDACCIÓN}

Coordinador editorial

Egea Vivancos, Alejandro [Didáctica de las Ciencias Sociales, Universidad de Murcia]

Secretaria

Arias Ferrer, Laura [Didáctica de las Ciencias

Sociales, Universidad de Murcia]

Editores

Jiménez Vialás, Helena [Historia Antigua, Universidad de Murcia]

Martínez Gil, Tània [Didáctica de las Ciencias

Sociales, Universidad de Barcelona]

Meseguer Gil, Antonio José [Historiador, Profesor de

Secundaria]

Ortiz García, Jónatan [Arqueología, Universidad de

Alcalá de Henares]

Romero Molero, Alberto [Arqueología, Universidad

Isabel I]

Sáez Giménez, David Omar [Historiador, Profesor

de Secundaria]

Sáez Rosenkranz, Isidora V. [Didáctica de las

Ciencias Sociales, Universidad de Barcelona]

Sánchez Mondejar, Celso Miguel [Arqueólogo,

Patrimonio Inteligente]

Responsable informático

Martínez García, José Javier [CEPOAT, Universidad de Murcia]

Responsables de traducción y corrección lingüística Martínez Martínez, Cristina [Profesora de Secundaria, Sociedad Española de Lenguas Modernas] Albaladejo Albaladejo, Sara [ISEN-Universidad de Murcia]

\section{CONSEJO ASESOR}

Adroher Auroux, Andrés María [Arqueología, Universidad de Granada]

Albero Muñoz, $M^{a}$ del Mar [H. ${ }^{a}$ del Arte, Universidad de Murcia]

Alia Miranda, Francisco [Historia Contemporánea, UCLM]

Arciniega García, Luis [Historia del Arte, Universidad de Valencia]

Barrio Barrio, Juan Antonio [Historia Medieval,

Universidad de Alicante]

Castellano i Solé, Núria [Egiptología, Schola

Didàctica Activa S.L.]

Chapman, Arthur [History Education, University

College of London, Reino Unido]

Cid López, Rosa María [Historia Antigua, Universidad de Oviedo]

Cobacho López, Ángel [Derecho, Universidad de Murcia]

Cuenca López, José María [Didáctica de las Ciencias Sociales, Universidad de Huelva]
Egea Bruno, Pedro M. ${ }^{a}$ [Historia Contemporánea, Universidad de Murcia]

Feijoo Martínez, Santiago [Arqueología, Consorcio

Ciudad Monumental de Mérida]

García Atienzar, Gabriel [Prehistoria, Universidad de

Alicante]

Ginestí Rosell, Anna [Filología Clásica, Katholische

Universität Eichstätt-Ingolstadt]

González Monfort, Neus [Didáctica de las

Ciencias Sociales, Universidad Autónoma de

Barcelona]

González Soutelo, Silvia [Arqueología, Universidad de Vigo]

Haber Uriarte, María [Prehistoria, Universidad de Murcia]

Hernández de la Fuente, David [Filología Clásica, Universidad Complutense]

Hutson, Scott R. [Anthropology, University of Kentucky, EEUU]

Igual Luis, David [Historia Medieval, UCLM]

Irigoyen López, Antonio [Historia Moderna,

Universidad de Murcia]

Jover Maestre, Francisco Javier [Prehistoria,

Universidad de Alicante]

Mahony, Simon [Digital Humanities, University College of London, Reino Unido]

Marsilla de Pascual, Francisco Reyes [Técnicas

historiográficas, Universidad de Murcia]

Martínez-Burgos García, Palma [H. ${ }^{a}$ del Arte, UCLM]

Mathis, Christian [Didaktik der Geschichte, PH Zürich]

Miralles Maldonado, José Carlos [Filología Clásica,

Universidad de Murcia]

Molina Gómez, José Antonio [Historia Antigua,

Universidad de Murcia]

Mónica Ghirardi [Historia Moderna, Universidad

Nacional de Córdoba, Argentina]

Navarro Espinach, Germán [Historia Medieval,

Universidad de Zaragoza]

Noguera Celdrán, José Miguel [Arqueología,

Universidad de Murcia]

Ortiz Heras, Manuel [Historia Contemporánea, UCLM]

Panzram, Sabine [Historia Antigua, Universität

Hamburg]

Pérez Molina, Miguel Emilio [Filología Clásica,

Universidad de Murcia]

Prados Martínez, Fernando [Arqueología,

Universidad de Alicante]

Sánchez lbáñez, Raquel [Didáctica de las Ciencias

Sociales, Universidad de Murcia]

Sancho Gómez, Miguel Pablo [Educación, UCAM]

Victoria Moreno, Diego [Historia Contemporánea,

UNED]

Vilar García, María José [Historia Contemporánea,

Universidad de Murcia]

Vivas Sainz, Inmaculada [H. ${ }^{a}$ del Arte, UNED]

Zamora López, José Ángel [Próximo Oriente Antiguo,

CCHS-CSIC] 



\section{Índice}

\section{Artículos}

Las ocupaciones paleolíticas en el sur de la provincia de Albacete

Noelia Sánchez Martínez

El elefante en las acuñaciones hispanocartaginesas

José Luis Aledo Martínez

La epigrafía votiva romana de Caldas de Montbui (Vallés Oriental, Barcelona) (ss. I-II d. C.). Un ejemplo de promoción de las élites provinciales de la tarraconensis en centros de aguas mineromedicinales

Jesús Sánchez Alguacil

Representación de la historia de España por medio de la filatelia. Estudio de los sellos diseñados por Gallego y Rey

Pedro Vázquez-Miraz

La representación del patrimonio arqueológico en los libros de texto de Educación Primaria: EI 109 contexto indígena canario como estudio de caso

A. José Farrujía, Carmen Ascanio Sánchez, Ulises Martín Herández y Cristo Manuel Hernández Gómez

La empatía como elemento para la adquisición del pensamiento histórico en alumnos de 129 bachillerato. Un estudio de caso centrado en la Guerra Civil española y el franquismo Sebastián Molina Puche y Adrián Salmerón Ayala

Fuentes orales para el desarrollo de la empatía histórica: un estudio en la formación del 155 profesorado de Educación Infantil

$M^{a}$. Teresa Carril-Merino, Beatriz Andreu-Mediero, Mercedes de la Calle Carrecedo y Esther López Torres

¿Qué aporta el género a la formación de docentes de historia? La valoración de la perspectiva de género entre los estudiantes del Máster de Profesor/Profesora en Educación Secundaria Helena Rausell Guillot

Educar para una ciudadanía crítica: una investigación a partir de los usos y finalidades de la historia escolar

Néstor Banderas Navarro

\section{Reseñas}

A. Brilli (2018). El viaje a Oriente, Madrid: A. Machado Libros, 390 págs Juan Álvarez García

Altamira (Hugh Hudson, 2016) 



\section{La empatía como elemento para la adquisición del pensamiento histórico en alumnos de bachillerato. Un estudio de caso centrado en la Guerra Civil española y el franquismo}

\section{Empathy as an Element of Acquisition of Historical Thinking in High School Students. A Case Study Focused on the Spanish Civil War and Franco's Era}

\author{
Sebastián Molina Puche \\ Universidad de Murcia \\ smolina@um.es \\ 0000-0003-1469-2100
}

\author{
Adrián Salmerón Ayala \\ Universidad de Murcia \\ adrian.salmeron@um.es \\ 0000-0001-5440-3110
}

Recibido: 24/09/2019

Aceptado: 07/05/2020

\begin{abstract}
Resumen
Este trabajo se centra en el análisis de la adquisición de la empatía histórica, una de las dimensiones de las llamadas competencias históricas, por parte de un grupo de alumnos de $2 .^{\circ}$ de Bachillerato de un centro educativo de la Región de Murcia. A partir de la realización de un juego de rol evolutivo ambientado en la Guerra Civil y el Franquismo, se ha realizado un estudio descriptivo con metodología cualitativa a partir de los datos obtenidos de la aplicación de varios instrumentos (relatos elaborados por el alumnado y un cuestionario), que estaban orientados a evaluar el nivel de adquisición de esa dimensión del pensamiento histórico. En este caso, aunque los resultados avalan la eficacia del programa (el $75 \%$ de los alumnos alcanza un nivel medio o alto de comprensión empática), las implicaciones en la mejora del rendimiento académico del alumnado son relativas.
\end{abstract}

\section{Palabras clave}

Educación, Interpretación histórica, Enseñanza de la Historia, Estudios de caso, Juego de rol.

\begin{abstract}
This paper focuses on the analysis of the acquisition of historical empathy, one of the dimensions of the so-called historical competences, by a group of students of $2^{\text {nd }}$ Baccalaureate from an educational centre in the Region of Murcia. From the realization of an evolutionary role play set in the Civil War and Franco, a descriptive study has been carried out with qualitative methodology in which the data obtained in various instruments (stories prepared by students and one questionnaire), have been analysed to try to assess the level of acquisition of that dimension of historical thinking. In this case, although the results endorse the effectiveness of the program $75 \%$ of students reach a medium or high level of empathic understanding), they also denote that the implications for improving student academic performance are relative.
\end{abstract}

\section{Keywords}

Education, Historical interpretation, History Instruction, Case Studies, Role Playing. 


\section{Introducción}

Desde que la enseñanza de la historia adquirió una dimensión institucional en el siglo XIX con el surgimiento de los Estados liberales, han sido varias las voces que han cuestionado el tipo de historia que debía enseñarse en los centros educativos. De hecho, ya en 1891 el catedrático alicantino Rafael Altamira, en su obra La enseñanza de la Historia (Altamira, 1997, reedición), criticó ferozmente las rutinas memorísticas y demandó un modelo de enseñanza de la historia que otorgase a los alumnos valores como la comprensión, el análisis crítico o el rigor (Merchán y Duarte, 2014). Ha sido, no obstante, en los últimos treinta años cuando el debate ha tomado mayor fuerza tanto a nivel internacional como nacional, y se ha mostrado la dicotomía entre el modelo de enseñanza de la historia de corte "tradicional" o "romántico" y el modelo "crítico" o "ilustrado" (Carretero, 2007; Molina, Miralles, Deusdad y Alfageme, 2017). El primero de ellos bebe del positivismo decimonónico que produjo "la creación de relatos de corte teleológico y determinista orientados a promover la identificación acrítica de la población hacia una determinada nación" (López, 2010).

El segundo modelo encuentra sus raíces en la racionalidad crítica de la llustración. Está ligado a la cientificidad de la historia, entendida no como un saber estático sino como una ciencia, un campo de conocimiento en permanente construcción, que tiene como finalidad que los alumnos comprendan la complejidad del mundo en que viven y potencien así su espíritu crítico (Gómez y Molina, 2017).

Estos dos modelos devienen antagónicos. El primero estimula la creación de identidades colectivas excluyentes al tener como centro discursivo el relato nacional, étnico o cultural basado en la diferencia entre el "nosotros" y "los otros". El segundo busca ayudar a la construcción de identidades múltiples o inclusivas (Carretero, Rosa y González, 2006).

Por ello, y ante la presente globalización y el alejamiento de los postulados uniformadores de los Estados-nación decimonónicos, la visión tradicional de la enseñanza de la historia debería tener cada vez menor cabida en nuestras aulas (Molina y Ortuño, 2019).

Frente al modelo memorístico e identitario, desde los años 70 (sobre todo a partir del History Project 13-16 británico, pronto adoptado por varios grupos de innovación pedagógica en España: Sallés y Santacana, 2016), las innovaciones e investigaciones en didáctica de la historia han trabajado en torno a un concepto que ha conseguido revolucionar, en favor del segundo modelo, las estrategias de enseñanza-aprendizaje con el desarrollo del denominado pensamiento histórico.

El presente artículo se encuentra enmarcado dentro de estos últimos estudios $y$, en concreto, en una de sus dimensiones: la empatía histórica. A partir de un estudio de caso desarrollado con alumnos de $2 .^{\circ}$ de Bachillerato, se analiza la respuesta obtenida en un juego de rol evolutivo en el que los alumnos tienen que construir un relato desarrollando la evolución histórica de unos personajes durante la Guerra Civil y el Franquismo. Este estudio nace, por tanto, de la necesidad de renovar la forma de enseñar historia para que ésta deje de ser una asignatura enunciativa e implique a los alumnos en la construcción del conocimiento, cumpliendo esa función social y cívica (Prats y Santacana, 2011) y, al mismo tiempo, consiguiendo acrecentar la motivación del alumnado en el desarrollo de la misma. 


\section{Marco teórico}

\subsection{Concepto, importancia e implementación del pensamiento histórico}

El pensamiento histórico se puede definir como el conjunto de destrezas y habilidades utilizadas por el historiador en la construcción del conocimiento histórico. Éthiers, Demers y Lefrançois (2010) lo definen como un constructo metódico que integra tanto la perspectiva temporal como la interpretación crítica. Santisteban (2010) señala que este pensamiento histórico precisa de cuatro operaciones: pensar en el tiempo, dotar de una explicación causal e intencional, desarrollar las capacidades para la empatía e interpretar fuentes. No obstante, una de las obras que mayor difusión ha tenido acerca de estos conceptos ha sido la de Seixas y Morton (2013), quienes presentan seis grandes conceptos metodológicos fundamentales: relevancia histórica, trabajo con fuentes históricas, cambio y continuidad, causas y consecuencias, perspectiva histórica, y, por último, la dimensión ética, que han acabado por convertirse, de manera prácticamente generalizada, en los elementos de referencia del pensamiento histórico. De todas las citadas dimensiones, una de las que más interés ha suscitado en lo que a desarrollo de experiencias educativas innovadoras se refiere, ha sido la de perspectiva histórica, generalmente asimilada con la empatía histórica (Domínguez, 2015; González, Enríquez, Pagès y Santisteban, 2009). De hecho, el ya citado proyecto curricular History Project 13-16 -más tarde denominado School History Project-, vinculó la docencia con la investigación para la comprensión de conceptos estructurales de la Historia, como lo era la empatía (Miguel-Revilla y Sánchez, 2018a). De igual modo, trabajos pioneros como los de Dickinson y Lee (1978) focalizaron sus investigaciones en el análisis de las reacciones de los alumnos ante conceptos de segundo orden como prueba, causalidad o empatía, mientras que Shemilt (1984) llegaría a acuñar el término construcción empática.

El concepto de empatía proviene del campo de la psicología y fue acuñado por el alemán Theodore Lipps, quien utilizó el término Einfühlung para referirse a aquel que pierde la conciencia de sí mismo ante una pintura (u otro objeto artístico) y queda absorbido por este (Cairns, 1989; Chillón y Friera, 1998).

En el campo de la enseñanza de la historia, la empatía supone obligar al historiador a construir el conocimiento a través del acto de re-pensar (Domínguez, 2015) o reactualizar, que vendría a ser la capacidad para ponerse en el lugar de los agentes de los hechos históricos estudiados (Chillón y Friera, 1998). Así, la empatía es más que una identificación con un agente del pasado, pues se trata de comprender los fines y las intenciones de los personajes históricos, las situaciones en las que ellos actúan y las razones de sus actos (Cairns, 1989). Lee y Ashby (2001) señalan que la empatía histórica significa ser capaz de ver y considerar desde una posición apropiada, sin necesariamente asumir o compartir, las conexiones existentes entre las intenciones, las circunstancias y los actos de los agentes históricos, y que no se trata tanto de conocer que ciertos agentes y grupos históricos tenían una perspectiva propia, sino de ser capaz de esgrimir las repercusiones de esas perspectivas en un determinado contexto.

Seixas, por su parte, utilizando el término de perspective taking, apunta también en la misma dirección señalando que se trata del acto cognitivo de comprender los distintos contextos sociales, culturales, intelectuales, e incluso emocionales, que conformaron las vidas y actos de la gente en el pasado (Seixas, 2011). 
Foster (2001) reúne las principales características de la empatía histórica aportadas por autores anteriores. Así, en la empatía histórica predominan seis rasgos: supone comprender los actos de la gente en el pasado, aunque no comporta principalmente imaginación, identificación o afinidad en los sentimientos; implica una valoración exhaustiva del contexto histórico; promueve hacer conclusiones bien fundamentadas aunque provisionales; precisa de múltiples fuentes y perspectivas y requiere que los propios estudiantes examinen sus puntos de vista (Foster, 2001).

Una definición concisa del concepto es la que realiza Yilmaz (2007), quien señala que la empatía histórica es "la habilidad para ver y juzgar el pasado en sus propios términos intentando comprender la mentalidad, los marcos de referencia, las creencias, los valores, las intenciones y las acciones de los agentes históricos utilizando para ello las evidencias históricas" (p. 331 ).

Otro debate referido a la empatía histórica gira en torno al papel que ejerce ésta en la enseñanza. Con la intención de poner un poco de orden, Harris y Foreman-Peck (2014), plantean que la empatía en historia debe ser entendida de una forma tridimensional: una dimensión cognitiva para reconstruir, mediante pruebas, los pensamientos de los agentes históricos; otra dimensión en la que la empatía se comporta como una actitud o tendencia, puesto que se está eligiendo empatizar; $y$, por último, otra dimensión en la que la empatía es el entendimiento de los posibles sentimientos de personas del pasado comparados con los nuestros propios. No en vano, como indican Feliu y Hernández (2013), puede considerarse que se trata de "la esencia histórica por definición", ya que es "la praxis de ubicarse en el punto de vista de personas del pasado" (p. 18).

Como se ha podido comprobar, el concepto de empatía histórica, puesto en duda, problemático y ambiguo, sigue en construcción. $Y$ aunque se han podido vislumbrar algunos indicios de consenso, desde aquí se invita a una reflexión por parte de los investigadores y de los educadores para que avancen en la consecución de una definición precisa que delimite sus componentes y sus implicaciones conceptuales.

\subsection{La evaluación del desarrollo de la empatía histórica entre el alumnado}

Como hemos señalado, en el seno de las experiencias innovadoras británicas de los años setenta, la empatía fue uno de los rasgos más destacados (Domínguez, 2015). No obstante, no sería hasta el proyecto británico CHATA, a finales de los años 80 , cuando ésta comenzara a estudiarse como objeto didáctico (González et al., 2009). En todo caso, un problema al que se han enfrentado cuantos han diseñado y puesto en práctica innovaciones en este sentido ha sido la evaluación de los logros obtenidos por los usuarios. En este sentido, las investigaciones han seguido dos estrategias. Por un lado, se encuentran aquellas que entienden la empatía como un proceso heurístico, por lo que han planteado el desarrollo y evaluación de ejercicios empáticos de tres distintos tipos: los implicativos (utilizando la dramatización teatral), descriptivos (utilizando una proyección superficial del estudiante al agente histórico, reconstruyendo ambientes o situaciones históricas) $\circ$ explicativos (planteando tareas resolutivas, al tener que elegir entre unas determinadas opciones) (Chillón y Friera, 1998; Martín, 2010).

Por otro lado, desde la perspectiva de la psicología del aprendizaje, se han centrado en analizar el modo en que evoluciona en los sujetos la comprensión del pasado histórico, estableciendo diversos grados que oscilan desde uno nulo o mínimo de empatía (en el que para los alumnos las 
gentes del pasado eran inferiores intelectual y moralmente) a uno máximo en el que los alumnos asumen que la gente tenía las mismas capacidades intelectuales y morales que en la actualidad, pero diferentes valores y creencias, necesarias para la reconstrucción histórica (Berti, Baldin y Toneatti, 2009; Chillón y Friera, 1998). Estos estudios han dado lugar a la categorización de diferentes niveles de empatía histórica, que se presentan a continuación.

En EEUU se creó en 2012 el proyecto Reading like a Historian (https://sheg.stanford.edu/historylessons), que ha planteado una vía alternativa a las experiencias de empatía histórica inglesas estableciendo cuatro niveles de progreso: nivel 1) se realiza un juicio de los actores históricos según sistemas de valores actuales, nivel 2) no se valora la información histórica, nivel 3) se lleva a cabo una contextualización descriptiva, y nivel 4) se juzga históricamente la información de forma racional reconociéndose la propia subjetividad (Sáiz, 2013).

Tras un análisis comparativo de los modelos de progresión propuestos hasta 2015, Domínguez (2015) observa un gran consenso que permite hablar de cinco grandes niveles: nivel 1) incomprensión, nivel 2) explicación estereotipada, nivel 3) explicación desde la perspectiva de hoy, nivel 4) explicación desde la perspectiva histórica, y nivel 5) explicación contextualizada.

Volviendo a España, Sáiz (2013) llevó a cabo una actividad acerca de la conquista cristiana de la Valencia musulmana, en la que los alumnos debían escribir un relato en primera persona encarnando un personaje imaginario de los grupos sociales implicados. La tipología que utilizó se basaba en Ashby y Lee (1987), en Reading like a Historian y en el proyecto catalán de González et al. (2009). Otros trabajos sobre empatía histórica en España han sido los de Pizarro y Cruz (2014), quienes han trabajado la empatía referida a soldados de la Primera Guerra Mundial; Guillén (2016), sobre un ejercicio basado en las respuestas de los alumnos ante un relato protagonizado por un corsario y un bandolero en el siglo XVI; ○ Calderón y Arias (2017), centrado este último en la adquisición de perspectiva histórica por parte de alumnado de quinto curso de Educación Primaria.

Más recientemente contamos con los trabajos de Miguel-Revilla y Sánchez (2018b) y Molina y Egea (2018), que se han centrado en el desarrollo de la conciencia y la empatía histórica respectivamente. En el primer trabajo se centran en el análisis de la respuesta dada a un grupo de alumnos de cuarto curso de ESO a una pregunta sobre el mantenimiento de simbología franquista en distintas ciudades españolas. En este, se realiza un análisis cualitativo de las narraciones del alumnado que utiliza una categorización que sirvió de guía para el presente trabajo. En lo relativo al artículo de Molina y Egea (2018), se trata del análisis de un ejercicio de empatía histórica en $4 .^{\circ}$ de ESO, consistente en la elaboración de un relato en el que el alumno se convierte en un individuo que, terminada la Guerra Civil, es enviado a un campo de concentración nazi. Los autores han utilizado para evaluar la empatía histórica un nuevo modelo inspirado en la categorización de Lee y Ashby (2001), González et al. (2009) y Sáiz (2013) y en el que añaden además una gradación de niveles de complejidad (alto, medio, bajo e insuficiente) siguiendo los modelos de la tesis doctoral de Salazar (2016).

Basándonos en este último trabajo (Molina y Egea, 2018), el estudio de caso que nos ocupa parte del análisis de los datos obtenidos en el desarrollo de una actividad centrada en la empatía histórica, que ha sido llevada a cabo en un aula de $2 .^{\circ}$ de Bachillerato. Esta actividad ha consistido en el desarrollo de un juego de rol evolutivo ambientado en la España de la Guerra 
Civil y el Franquismo, en el que los alumnos han tenido que ponerse en el lugar de una persona cuya vida se desarrolló en esta época. Así, cada alumno ha recibido un primer relato introductorio que narraba, en primera persona, la situación familiar, laboral, geográfica y temporal de su personaje. A partir de aquí, y teniendo en cuenta que esta breve introducción terminaba en 1936, el alumnado, de forma individual, ha tenido que construir, con la finalidad de comprender las perspectivas de los agentes históricos, una narrativa en la que quedase reflejada la evolución histórica de dicho personaje desde el comienzo de la Guerra Civil hasta el final de la dictadura de Franco. Una vez realizada la actividad, se ha pasado a analizar los resultados de la misma haciendo uso de una metodología cualitativa en la que se han utilizado, como instrumento de recogida de datos, los propios relatos elaborados por el alumnado y dos cuestionarios: uno centrado en la adquisición de los contenidos del período histórico estudiado, y otro sobre la opinión que les merecía la propia actividad realizada. Los datos y su análisis se muestran en el apartado siguiente.

\section{Marco empírico: un estudio de caso en forno a la empatía histórica}

\subsection{Objetivos de la investigación}

El objetivo principal de esta investigación es analizar el nivel de adquisición de perspectiva histórica por parte del alumnado de $2 .^{\circ}$ curso de Bachillerato a través de un trabajo desarrollado en la asignatura de Historia en torno a la empatía histórica.

Para ello, se siguen tres objetivos específicos:

1. Averiguar si, por medio del desarrollo de acciones tendentes a potenciar la empatía histórica, el alumnado entiende la función social y cívica que tiene la enseñanza de la Historia.

2. Conocer el nivel de empatía histórica desarrollado por el alumnado participante.

3. Examinar si trabajar desde una perspectiva competencial facilita la adquisición de contenidos históricos escolares por parte del alumnado.

\subsection{Participantes}

La investigación que nos ocupa se llevó a cabo en un centro de Educación Secundaria (IES) en una localidad situada en la comarca de la Vega Media del río Segura (Murcia), durante el mes de abril de 2019. El IES está situado en un medio rural en una localidad en la que el $6 \%$ de la población activa se dedica a la agricultura, un $29 \%$ a la industria de la transformación agrícola y un $41 \%$ al sector servicios, el cual ha repuntado en los últimos años. El nivel de estudios de los padres de los alumnos del centro es también medio: un $30 \%$ tiene únicamente estudios primarios, el $60 \%$ estudios medios y solamente entorno al $10 \%$ tiene estudios universitarios. El aula en la que se desarrolla este estudio de caso está conformada por 29 alumnos, de los cuales 18 eran chicas y 11 chicos. Una mirada a la diversidad precisaría de dos anotaciones: uno de los alumnos presentaba dislexia y, en cuanto a la inmigración, uno de los estudiantes era de origen marroquí, aunque mostraba una sólida integración. Por último, resulta procedente añadir que estos alumnos no habían desarrollado anteriormente ningún tipo de ejercicios relacionados con la movilización de competencias históricas y, por tanto, tampoco ligados a la empatía histórica. 


\subsection{Diseño de la actividad e instrumentos de investigación}

\subsubsection{Diseño de la secuencia}

Para la realización de este estudio, se partió de la elaboración en el aula de una secuencia de trabajo denominada Cuadernos de vida, enmarcada dentro de una Unidad Didáctica de $2 .^{\circ}$ de Bachillerato que recoge los contenidos curriculares correspondientes a la Guerra Civil y la Dictadura Franquista (ubicados en los Bloques 11 y 12 del currículum de la asignatura de Historia de España de la Comunidad Autónoma de la Región de Murcia). La puesta en práctica de este tipo de secuencia requiere la utilización de competencias de pensamiento histórico, como el trabajo y análisis de fuentes, la contextualización y la perspectiva histórica, la identificación de procesos de cambio y continuidad, la causalidad histórica, y, por supuesto, la empatía histórica.

La actividad que sirve de base a esta investigación fue llevada a cabo por el alumnado como trabajo autónomo debido, especialmente, a la complejidad que comporta $2 .^{\circ}$ de Bachillerato: alta carga lectiva, dinámica de clase casi íntegramente dedicada a la preparación de la prueba de acceso a la Universidad, alto número de alumnos, estrecho margen temporal, etc.

Para el diseño de Cuadernos de vida, se ha contado con un amplio abanico de influencias y referencias. En primer lugar, la experiencia Viure i morir a la guerra civil enspanyola, 1936-1939 incorporada en Tribó (2005). En esta experiencia, desarrollada en el año 2000 por el Departamento de Didáctica de las Ciencias Sociales de la Universidad de Barcelona, se ofrecía al alumnado de Secundaria una propuesta didáctica centrada en la vida cotidiana durante la Guerra Civil, que consistía en hacer vivir a los alumnos la experiencia de cuatro personas (un soldado, un maestro, una lavandera, y la criada de un médico).

En segundo lugar, han sido también influyentes algunas de las experiencias innovadoras anteriormente citadas, como las de Sáiz (2013), Molina y Egea (2018) y González et al. (2009), para desarrollar un enfoque de trabajo basado en la construcción de relatos o narrativas históricas como método para impulsar la empatía histórica, desechando así una opción de respuestas múltiples o ejercicios puntuales sobre preguntas concretas de clase, al estilo que proponían Domínguez (1986) o Pizarro y Cruz (2014). Esto fue debido principalmente a la mayor complejidad y envergadura competencial que aporta la construcción de narrativas históricas, cuya elaboración y análisis, constituyen, para Voss y Wiley (2006, citado en Domínguez, 2015, p. 56), una de las tres habilidades del historiador.

Además, no se puede obviar la influencia que ha tenido también la lectura de la obra de Hernández (2016), quien reivindica la historia reciente como objeto de estudio en las aulas y su importancia para la construcción de una sociedad democrática, así como el artículo de Molpeceres (2006), quien apunta que, a pesar del alto interés del alumnado por la Guerra Civil y el Franquismo, los alumnos tienen conocimientos realmente escasos sobre estos temas. Estos dos aspectos llevaron finalmente a ubicar la experiencia innovadora en el curso y en los contenidos curriculares anteriormente citados.

El diseño de la actividad se centró en dos aspectos concretos: en primer lugar, la elaboración de los perfiles introductorios a la vida de sus personajes y, en segundo, la recopilación del material necesario que los alumnos debían consultar para desarrollar de forma autónoma las perspectivas y evolución histórica de los mismos. 
En cuanto a los perfiles introductorios, cada alumno contaba con un personaje distinto y, por tanto, cada uno partía desde una perspectiva diferente (Anexo I). La confección de dichos perfiles estuvo inspirada en testimonios reales extraídos del Banco de testimonios de la Generalitat de Catalunya, el archivo del proyecto Madres e Hijas de la Transición Española (mujerymemoria.org), el portal web La guerra de nuestros abuelos, biografías presentes en la página web de la Fundación Pablo Iglesias o de la Fundación Francisco Franco, en el portal web Todos los nombres, el de la CNT de Puerto Real, el Diccionario Bibliográfico Español recogido en la web de la Real Academia de la Historia y el portal web dedicado a los brigadistas internacionales Sobre Gales y la Guerra Civil Española.

El criterio seguido para el diseño de dichos perfiles fue la búsqueda del equilibrio dentro de la diversidad. El género de los personajes y el de los alumnos fue respetado, intentando con ello favorecer la construcción empática. El diseño estaba destinado para que existiera un reparto equitativo entre hombres susceptibles de apoyar o participar en el bando republicano (5) y de apoyar o participar en el bando sublevado (6). En cuanto a las mujeres, se consideró crear una gran disparidad de perfiles, desde criadas o lavanderas hasta una diputada del gobierno republicano o una mujer con un importante papel en la carlista Comunión Tradicionalista. De ellas, 8 serían susceptibles de apoyar al régimen republicano, 2 al nuevo régimen franquista y 11 no parecerían mostrar, en principio, ningún interés en la política. Este desequilibrio obedeció especialmente a los resultados encontrados en las fuentes y testimonios orales consultados, que correspondían a una mayor presencia de mujeres que apoyaban al gobierno republicano.

En cuanto al material aportado, denominado Caja de Recuerdos, estaba compuesto de fuentes primarias y secundarias que el alumnado debía consultar y analizar para construir su relato. Los criterios para seleccionar este material fueron (1) que albergara la mayor parte de las sensibilidades, (2) que reuniera una gran cantidad de testimonios, (3) que abarcara contenidos de las formas de vida, (4) que contara con material de prestigiosos historiadores y (5) que, además, presentara también otro tipo de material como películas o canciones de la época.

A partir de las breves introducciones, del material aportado por el docente, de las anotaciones tomadas en clase y del propio material lectivo de la asignatura, los alumnos tuvieron que construir un relato sobre la vida de sus respectivos personajes desde el punto de vista de los mismos, con el fin de desarrollar la capacidad empática histórica.

En cuanto a la normativa impuesta, esta presenta las siguientes reglas: el personaje no podía morir, el relato debía ser redactado en primera persona, la historia debía ajustarse a la realidad histórica, debía contar con un mínimo de dos páginas, se recomendaba que un relato ocupara todas las épocas estudiadas, y era importante un apartado final de bibliografía/webgrafía. Además, esta normativa señalaba, a modo de elemento novedoso y motivador, la permisividad de faltas de ortografía e incluso el uso de lenguaje coloquial, en caso de que el personaje a recrear tuviera un bajo nivel cultural. En este proyecto se apostaba por brindar libertad a los alumnos para reproducir las vidas y perspectivas de sus personajes, en la línea de lo que señalan Molina y Egea (2018) de no limitar la originalidad del alumnado, por lo que no se pusieron mayores límites que un amplio espacio temporal (1936-1975). 


\subsubsection{Instrumentos para la obtención de datos}

Con el fin de responder al objetivo principal del proyecto -el nivel de adquisición de perspectiva histórica del alumnado de $2 .^{\circ}$ curso de Bachillerato a través de un trabajo desarrollado en la asignatura de Historia en torno a la empatía histórica- se han utilizado dos instrumentos de obtención de datos: los propios relatos y un cuestionario de opinión.

\section{a. Los relatos}

El análisis de las construcciones narrativas presentadas por el alumnado -cuyos ejemplos más significativos se pueden ver en las páginas siguientes- ha sido utilizado para responder a los siguientes objetivos.

Por un lado, estos relatos se han utilizado para conocer el nivel de adquisición del objetivo específico 1 (cumplimiento de la función social y cívica de la enseñanza de la historia), a través de la evaluación mediante rúbrica de los niveles de empatía alcanzados por los alumnos, ya que la capacidad de comprensión del punto de vista de su personaje supondrá el desarrollo de la empatía deseada que cumple con dicha función.

Para dar respuesta al objetivo específico 2 (conocer el nivel de empatía histórica desarrollado por el alumnado participante), se llevó a cabo un análisis riguroso del contenido de los relatos por medio de una rúbrica realizada ad hoc, y que puede consultarse en la Tabla 1. Además, los relatos también fueron utilizados para responder al objetivo específico 3 (examinar si trabajar desde una perspectiva competencial facilita la adquisición de contenidos históricos escolares por parte del alumnado) siguiendo una serie de criterios en su análisis: la introducción de conocimientos históricos significativos explicados en clase $\mathrm{y} / \mathrm{o}$ aprehendidos en su proceso autónomo de construcción del conocimiento; explicaciones correcta del proceso histórico; la existencia de errores históricos significativos y la validez de las fuentes consultadas por los alumnos.

Pese a que fueron 29 estudiantes los que participaron en la propuesta señalada, el número de relatos entregados por el alumnado fue de 28 , ya que uno de los alumnos no hizo entrega del mismo.

\section{b. El cuestionario de opinión}

El otro instrumento utilizado fue un cuestionario anónimo creado para conocer la percepción general de los alumnos acerca de la experiencia tratada. En este cuestionario, respondido por todos los participantes (29), el alumnado ha tenido que reflejar su grado de conformidad o discrepancia en una escala Likert de 5 elementos en torno a veinte cuestiones planteadas en base a siete criterios generales: la idoneidad en tiempo y espacio de la actividad, la práctica como instrumento motivacional, la utilidad del ejercicio para su formación histórica, la finalidad empática del mismo, la idoneidad del material aportado, otras cuestiones relativas a la mejora del ejercicio y, por último, un apartado de comentarios y/o sugerencias. Las cuestiones planteadas pueden ser consultadas en la tabla 3.

Con este instrumento, se pretendía responder también al objetivo específico 3 (examinar si trabajar desde una perspectiva competencial facilita la adquisición de contenidos históricos 
escolares por parte del alumnado). En este sentido, en respuesta a lo planteado por Almansa (2018), se creó un espacio específico para preguntar a los alumnos si el ejercicio había conseguido aumentar su motivación por la asignatura, mientras que el resto de preguntas giraban en torno a si la experiencia les había facilitado el estudio para el cuestionario de conocimiento de contenidos, y si les había permitido aprender cosas nuevas que no habían visto en clase.

\subsection{Procedimiento de análisis de datos}

El material entregado por el alumnado se utilizó como una de las herramientas de recogida de datos de la investigación. Para el análisis de los datos aportados, se utilizó una rúbrica, inspirada en Molina y Egea (2018) y fundamentada en la categoría empática denominada empatía histórica contextualizada, considerada por los diferentes autores como el nivel más alto alcanzable en los modelos de progresión empática (Domínguez, 2015; Molina y Egea, 2018; Sáiz, 2013).

Como se puede observar en la rúbrica (Tabla 1), esta categoría concentra tres criterios básicos: la precisa contextualización, la realización de juicios sobre el pasado en función de los valores del pasado y la capacidad para relacionar estos valores con los del presente. En función del nivel de los criterios alcanzados, se obtendrá una mayor o menor calificación.

Los criterios fundamentales de esta empatía histórica contextualizada beben directamente de aquellos establecidos por Foster (2001) como esenciales para evaluar la empatía histórica, véase: indicar que el pasado es diferente del presente; explicar las perspectivas que se toman y sus consecuencias; desarrollar perspectivas objetivamente precisas basadas en las evidencias históricas $y$, finalmente, la habilidad de distinguir entre las perspectivas pasadas y las presentes (Foster, 2001, pp. 175-178). Además, esta categorización de la empatía tiene mucho que ver también con las tesis clásicas de Leopold von Ranke, que indican que el pasado es diferente del presente y no debería ser juzgado con los valores del presente (Harris y Foreman-Peck, 2014, p. $3)$.

\section{Tabla 1}

Rúbrica de evaluación de la competencia de empatía histórica contextualizada

\begin{tabular}{ll}
\hline Nivel & Criterios de análisis \\
\hline Nivel alto & $\begin{array}{l}\text { Contextualización de forma precisa; realización de juicios sobre el pasado } \\
\text { en función de los valores del pasado, relacionándolos con el presente. }\end{array}$ \\
Nivel medio & $\begin{array}{l}\text { Contextualización poco elaborada, emisión de juicios sobre el pasado en } \\
\text { función de los valores del pasado de forma correcta, pero sin comparaciones } \\
\text { con el presente. } \\
\text { Nivel bajo }\end{array}$ \\
& $\begin{array}{l}\text { Contextualización mínima, emisión de juicios valorando el pasado de forma } \\
\text { incorrecta. No hay perspectiva histórica sino que abunda el presentismo. Se } \\
\text { trata de una empatía histórica presentista. } \\
\text { Nivel insuficiente }\end{array}$ \\
Contextualización mínima. No hay emisión de juicios ni valores. Predomina la \\
mera descripción.
\end{tabular}

Fuente: elaboración propia. 
Pero, además, este nivel de empatía se nutre conceptualmente de las investigaciones que, desde los años 80 , han tratado de concretar una categoría máxima en los modelos de progresión de empatía histórica. Así, esta categoría se sustenta en el nivel 4 de Shemilt (1984), el nivel 5 de Ashby y Lee (1986), el nivel 5 de la categorización de consenso propuesta por Domínguez (2015), el nivel 4 de Sáiz (2013) y, por último, en la categoría de empatía histórica contextualizada de Molina y Egea (2018), que recogía ya, además, el cuarto nivel propuesto a posteriori por González et al. (2009).

\section{Resultados}

\subsection{Resultados de los relatos}

De acuerdo con la rúbrica propuesta de empatía histórica contextualizada (Tabla 1), revela que los niveles alcanzados por el alumnado $(\mathrm{N}=28)$ han sido los siguientes (Tabla 2): un $25 \%(\mathrm{n}=7$ ) ha logrado el nivel alto -porcentaje similar a Molina y Egea (2018) y a Sáiz (2013)-, el 50\% $(n=14)$ el nivel medio y un $18 \%(n=5)$ el nivel bajo. Solo un $7 \%(n=2)$ han obtenido un nivel insuficiente. De aquí se extrae que, aunque solo un cuarto de la muestra logra cumplir con todos los requisitos para obtener esta competencia empática, se comprueba, sin embargo, que un $75 \%$ ha conseguido superar holgadamente la presente prueba con nivel medio 0 alto (porcentaje similar al de la investigación de Domínguez en 1986). Esto permite afirmar que el desarrollo de la empatía histórica ha tenido éxito entre el alumnado y que, por tanto, esta experiencia ha servido para desarrollar la función social y cívica de la historia (objetivo específico 1).

Tabla 2

Muestreo de los niveles que han adquirido cada uno de los distintos relatos

\begin{tabular}{llll}
\hline Nivel & Código & Total & Porcentaje \\
\hline Nivel alto & $5,13,16,18,25,27,28$ & 7 & $25 \%$ \\
Nivel medio & $3,4,7,8,9,10,11,12$, & 14 & $50 \%$ \\
& $15,19,20,23,24,29$ & & $18 \%$ \\
Nivel bajo & $21,22,26,30,32$ & 5 & $7 \%$ \\
Nivel insuficiente & 14,17 & 2 & \\
\hline
\end{tabular}

Fuente: elaboración propia.

Como ejemplo de un relato considerado como de nivel alto, contamos con el número 5 . En este se realiza una contextualización precisa:

[05] (...) todo se torció aquel 19 de julio de 1936, cuando las tropas de los sublevados llegaron a Villadiego, donde hubo un foco de oposición que fue duramente reprimido por la Guardia Civil y los milicianos de derechas.

Se detecta una correcta emisión de juicios sobre el pasado con valores del pasado:

[05] Las noches eran mi momento favorito del día, era un momento padre e hija, él me leía cuentos, como La buena Juanita, siempre me decía que tenía que ser como Juanita, cariñosa con todo el mundo, buena estudiante y siempre aprendiendo de mi madre a cómo hacer las tareas del hogar. Un día normal en mi casa en Villadiego era mi madre cosiendo mi ajuar, yo aprendiendo a su lado a hacer punto de cruz, mis hermanos jugando y mi padre en la pescadería (...). 
Se aprecia además una correcta comparativa con el presente:

[05] A día de hoy, cada vez que hablo con mi nieta sobre la gran España del pasado, ella me rebate diciendo que no entiende cómo podía vivir así, y yo siempre le digo que cómo trata ella de defender tonterías como la igualdad hombre-mujer, si como decía la gran sabia Pilar Primo de Rivera "La vida de toda mujer, a pesar de cuanto ella quiera simular -o disimular- no es más que un eterno deseo de encontrar a quien someterse".

Profundizando en los resultados, el nivel más repetido (la mitad de la muestra con la que se contaba) ha sido el de nivel medio. Esto significa que, aunque estos alumnos han contextualizado y han tenido la habilidad de elaborar juicios sobre el pasado con valores del pasado, sin embargo, no han sido capaces de relacionarlos con los del presente.

Se trata de relatos como el del alumno número 3 , en el que se realiza una contextualización adecuada:

[03] Cuando estalló la guerra civil, a mí no me llamaron, pero a mi hermano mayor sí y tuvo que irse a las milicias, por desgracia en las jornadas de mayo del 37, donde los comunistas querían eliminarlas, recibió un tiro en el pecho y lo mataron (...).

Y se emiten juicios sobre el pasado en función de los valores del pasado:

[03] La industria donde trabajaba entró en quiebra y me vi obligado a dejar a mi mujer y al niño allí e irme a Alemania con mi hermano a trabajar (...) Mi hermana se quedó cuidando de nuestros padres que ya estaban mayores.

En lo relativo a los relatos considerados como de nivel bajo, el del alumno número 26 puede ser muy ilustrativo. Este posee una contextualización poco elaborada:

[26] Tras el estallido de la guerra civil seguí del lado comunista y para luchar por la República Española y en contra del fascismo (...).

Cuenta también con una visión presentista de los hechos narrados:

[26] "Provengo de una familia minera, fui educado en los valores del trabajo, el esfuerzo y el sacrificio (...) Con 14 años entré por primera vez a trabajar en la mina. Empecé a media jornada pues todavía estaba estudiando (...).

Por último, el relato del alumno 14 es buen ejemplo del nivel de empatía insuficiente, con un carácter más literario que propiamente histórico:

[14] Conforme iban pasando los meses, nos íbamos adaptando a nuestra nueva vida. El ambiente en casa era mejor, mi padre se encontraba muy bien en su nuevo trabajo, yo hice nuevas amistades que me hicieron encontrarme muy bien en mi nueva vida, etc. (...) Los rincones de mi casa dejan constancia de mi lucha: cuadros que mi padre aprendió a trazar cuando pagaba sus ideas socialistas en prisión; recuerdos de mi hermano, condenado a trabajos forzados en el Valle de los Caídos... Incluso algún vecino vengativo que jugó a delatarnos. 


\subsection{Resultados del cuestionario de opinión}

Como se ha señalado anteriormente, el cuestionario de opinión tenía como finalidad principal conocer la percepción del alumnado sobre su proceso de aprendizaje (relacionado con los objetivos específicos número 2 y 3). En este sentido, las respuestas del cuestionario (Tabla 3) no dejan lugar a dudas.

\section{Tabla 3}

Resultados del cuestionario de opinión (a. Totalmente en desacuerdo; b. En desacuerdo; c. Ni de acuerdo ni en desacuerdo; d. De acuerdo; e. Totalmente de acuerdo)

Preguntas

1. No ha sido una buena idea realizar esta práctica en $2^{\circ}$ de Bachillerato debido a la carga lectiva que de por sí ya presenta este curso.

$\begin{array}{llllll}\text { 2. Me hubiera gustado haber realizado este tipo de actividades en cursos } & 0 & 0 & 2 & 10 & 17\end{array}$ anteriores.

$\begin{array}{llllllll}\text { 3. Considero que sería una buena idea trazar todo un curso desarrollando } & 2 & 4 & 8 & 9 & 6\end{array}$ la vida de un personaje ficticio para comprender la Historia de una manera más cercana.

4. El juego ha conseguido despertar mi interés por la Guerra Civil española y el Franquismo.

5. Este trabajo ha conseguido motivarme y aumentar mi interés por la Guerra Civil y el Franquismo.

6. Haciendo mi trabajo he descubierto y aprendido cosas que no hubiera aprendido en clase o a través de los apuntes.

7. El juego ha sido motivador.

8. Recomiendo esta actividad para los alumnos del próximo año.

9. Tras haber realizado la práctica, me ha resultado más fácil estudiar para el examen.

10. El juego ha sido útil para mi formación en Historia.

11. Pienso que con este tipo de actividades puedo aprender más Historia que con las clases clásicas.

12. El juego me ha hecho plantearme cuestiones que no me habría planteado siguiendo el curso normal de clase.

13. He conseguido empatizar/ponerme en la piel de mi personaje.

14. He podido desarrollar habilidades de investigador y de historiador para construir mi relato.

15. Ha sido una experiencia innovadora.

16. El material aportado por el profesor ha sido útil.

17. El material aportado por el profesor ha sido excesivo.

$\begin{array}{lllll}0 & 0 & 4 & 13 & 12 \\ 1 & 2 & 7 & 12 & 7 \\ 0 & 0 & 3 & 12 & 14 \\ 0 & 1 & 1 & 13 & 3 \\ 1 & 4 & 5 & 8 & 11 \\ 0 & 3 & 6 & 9 & 11 \\ 0 & 0 & 6 & 13 & 10 \\ 0 & 1 & 5 & 13 & 10 \\ 0 & 1 & 6 & 12 & 10 \\ 0 & 0 & 6 & 10 & 13 \\ 0 & 0 & 8 & 15 & 6 \\ 0 & 0 & 1 & 9 & 19 \\ 1 & 0 & 1 & 12 & 15 \\ 7 & 6 & 6 & 4 & 6\end{array}$


18. Me hubiera gustado contar con más herramientas e instrumentos de investigación.

19. He contado con la ayuda y guía del profesor en todo momento.

20. Me hubiera gustado compartir la experiencia de mi personaje con las experiencias de los personajes del resto de la clase a través de actividades alternativas: entrevista, juegos de preguntas, recreaciones, etc.

1

$\begin{array}{ll}4 & 8 \\ 5 & 13\end{array}$

Fuente: elaboración propia.

A destacar la buena opinión que tienen sobre la idoneidad del momento en el que se desarrolla el proyecto empático y el tiempo que ocupa (ítems 1 a 3), aunque casi un tercio de los alumnos (10 de 29) consideran que no es buena idea la realización de actividades de este tipo en $2^{\circ}$. de Bachillerato. En lo relativo a su opinión sobre la capacidad de motivación de la actividad (preguntas 4 a 8), aunque más de la mitad de los alumnos encuestados (19 de 29) afirman que ha aumentado su interés por la Guerra Civil (pregunta 4), cuando se les pregunta directamente por su opinión sobre la motivación alcanzada tras la actividad (pregunta 7), solo 16 de los 29 alumnos admiten estar de acuerdo o muy de acuerdo con ello. En relación a la utilidad del ejercicio para su formación histórica (preguntas 9 a 12), destaca, en primer lugar, que 23 estudiantes afirman que el juego ha sido útil para su formación en Historia (preguntas 10 y 11 ), y 20 alumnos consideran que, tras la actividad, les ha resultado más fácil estudiar para el examen (pregunta 9).

En cuanto a las dos dimensiones restantes (finalidad empática de la actividad, ítems 13 a 15, e idoneidad del material entregado, ítems 16 a 20) las respuestas son, en términos generales, elocuentes: 28 de los 29 alumnos celebran el carácter innovador de la actividad (pregunta 15), mientras que 24 de los 29 admiten haber contado con la ayuda del profesor.

En definitiva, y en términos generales, las respuestas de los alumnos confirman que con este tipo de actividad se puede aprender más historia que con la metodología tradicional, un punto que se manifiesta también a partir de los comentarios donde algunos alumnos se referían a esta cuestión en los siguientes términos: "He aprendido mucho" o "Creo que ha sido un trabajo muy interesante que no se nos había planteado antes". Por todo ello, resulta evidente tanto desde el punto de vista de los alumnos como del análisis de sus relatos, que el ejercicio ha tenido un resultado positivo en cuanto a la construcción de conocimiento histórico.

\section{Análisis de resultados}

De acuerdo a cada uno de los criterios fundamentales de la rúbrica (precisión en la contextualización, realización de juicios sobre el pasado en función de los valores de la época analizada, y capacidad para relacionar estos valores con los del presente), merece la pena desgranar los resultados obtenidos en los relatos (Tabla 4).

En cuanto a la presencia de una contextualización precisa, esta se halla en el $36 \%$ de los relatos $(\mathrm{n}=10)$; porcentaje al que le siguen 9 de los mismos que han sido contextualizados de forma poco elaborada y, finalmente, los otros 9, que han sido contextualizados mínimamente. 
Tabla 4

Niveles de contextualización: número total y porcentaje de respuesta $(N=28)$

Nivel de contextualización

Número de relatos

Precisa

$10(36 \%)$

Poco elaborada

$9(32 \%)$

Mínima

$9(32 \%)$

Nula

0

Fuente: elaboración propia.

En cuanto a la emisión de juicios sobre el pasado asumiendo los valores del pasado, los resultados revelan que en 7 de las narrativas se logra su mayor nivel, en 7 se asumen los valores del pasado de forma errónea y en 14 narrativas no se realiza ningún tipo de juicio.

Un ejemplo de enjuiciamiento del pasado con valores propios de la época lo encontramos, por ejemplo, en la narración número 19:

[19] Al principio hacía lo que me decían porque para mí no significaba nada y porque mi padre decía había que respetar las creencias de los demás, y yo respetaba a mi padre, mucho.

La relación de los valores del pasado con los del presente se encuentra en 7 de los ejercicios evaluados. Los relatos que lo han conseguido han sido los que han alcanzado el nivel más alto de empatía histórica contextualizada. Un aspecto destacable es que la comparación entre valores del pasado y valores del presente ha estado protagonizada en la mitad de las ocasiones por aspectos de desigualdad de género y realizados por alumnas, lo que demuestra, el actual interés de los adolescentes por estos temas, y la utilidad de esta experiencia para con esa función social y cívica. Este tipo de respuesta tiene como mejor exponente el relato número 25 :

[25] Atanasio desapareció, no quiso hacerse cargo de nuestra hija. En ese entonces era imposible imaginarse una madre soltera, al contrario que ahora, que la mayoría lo son, y tan felices. $Y$ aunque madre me apoyaba a pesar de los comentarios del pueblo y de las vecinas, ya sabes que nuestro padre no tenía tanto tacto, y no podía aguantar la vergüenza que le producía mi presencia en casa, por lo que decidió mandarme a un centro religioso en Murcia. Bien lejos, para que pudierais creer que estaba muerta. En este sitio mi vida se basó en coser y rezar, para demostrar lo arrepentida que estaba de mi "pecado".

Por último, en el caso de los juicios erróneos sobre el pasado, no todos ellos desembocan necesariamente en elementos presentistas, es más, éstos últimos solo se encuentran en uno ellos, en el relato 14. En cuanto a elementos claramente presentistas, éstos se encuentran en 6 de los relatos, una cifra nada desdeñable, con ejemplos como el relato número 11 :

[1 1] Casi 3 años de guerra entre españoles nos dejó un país devastado y dividido. Fue el bando sublevado el ganador de la contienda. A nosotros nos quedaron pocas opciones de vivir en paz: exilio o represión, cuando no fusilamiento. Elegí exilio y pude llegar a uno de los barcos atracados en el puerto de Gijón con destino a Francia.

O como los detectados en el relato número 12: 
[12] Me crié en un pueblo rodeada de mis hermanos, era un poco difícil ya que ellos no me entendían, mis tres hermanas eran las mayores y pues claro solo me hacían caso cuando mi madre se lo pedía y los otros tres, dos de ellos eran gemelos y siempre estaban juntos y el otro solo me sacaba 1 año y no es que me entendiera mucho.

Con respecto a este último bloque de narrativas, en las que se emiten juicios erróneos del pasado, cabe destacar que la mayor parte de ellas se han empleado elementos de una empatía histórica meramente descriptiva, que se acercaría más a la denominada empatía histórica simple de Sáiz (2013) y González et al. (2009), consistente en la descripción de hechos contextuales de los que el personaje forma parte, pero de los que no se extrae ninguna valoración ni juicio al respecto. Este extremo puede observarse en el relato número 13:

[13] Mi misión, junto a la de muchos otros encarcelados como yo, fue la de cavar trincheras a primera línea de fuego, escuchando a cada momento explosiones, metralletas y algún quejido que otro de algún soldado, temerosos por mi alguna bala nos alcanzaba a nosotros (...) tras estar en Belchite, me mandaron a Jaca, a Teruel y por toda la sierra de Almantes a cavar trincheras como un condenado. (...) Una anécdota de limosna. No recuerdo bien el año, pero salió mi mujer a pedir algo para comer mientras yo me quedaba con mi hijo en casa. Tras toda la mañana intentando conseguir un alimento que echarnos a la boca, regresamos a casa y mi hijo le dijo a su madre "iqué traes mamá?" y mi mujer con los ojos llorosos le dijo "Tres almendricas...".

Además, se han hallado dos casos en los que el alumno ha representado casi teatralmente a su personaje sin profundizar en las ideas del mismo, las intenciones de sus actos o su cosmovisión, riesgo del que ya advertía Hernández $(2015$, p. 144). Se trata de los relatos número 30 y 32:

[30] La forma en que esa gente quería romper la unidad de España era digno de castigar, tal y como decía nuestro gran fundador José Antonio, que fue acusado de conspiración y rebelión militar contra el Gobierno de la Segunda República. (...) Una acusación totalmente injusta ya que eran los propios republicanos los que atentan contra nuestro querido país. Pero este hecho no quedará impune.

[32] Crecí rodeado de gente buena y tradicionalista que me enseñaba buenos valores, no como los de esos rojos que no creían en Dios y que se aprovechaban del trabajo de los demás.

Ambos casos, además, corresponden a una contextualización mínima y a un nivel bajo de empatía histórica contextualizada. Una primera hipótesis que se puede esbozar es la posible desmotivación que ha podido generar en estos alumnos los perfiles entregados, casualmente ambos muy similares: hijos de familias de pequeños propietarios, fervientemente católicas y con inquietudes políticas dirigidas al falangismo. El poco interés, la baja motivación (Almansa, 2018) del alumnado frente a estos perfiles puede ser la causa explicativa de que los relatos no hayan superado el límite mínimo establecido, sus discursos estuvieran poco elaborados y el apartado bibliográfico fuera verdaderamente insuficiente.

Por último, existen dos ejemplos que pueden mostrar de forma explícita la función social y cívica de este ejercicio, a través de mensajes aleccionadores que extraen los personajes de sus vivencias (objetivo específico 1, en respuesta a lo expuesto, entre otros, por Miguel-Revilla y Sánchez, $2018 b$; y Prats y Santacana, 2011). Ahora bien, esto hay que tomarlo con precaución, puesto que es complicado averiguar a través de estos fragmentos si los alumnos realmente extraen estas 
conclusiones o si, como tarea de identificación, únicamente señalan el punto de vista del agente histórico en su contexto. Ejemplo de esto sería el también aleccionador, pero nada democrático, que aparece en el relato número 5 :

[5] En 1975, el Generalísimo Francisco Franco fallece, y el pueblo se divide en quienes quieren continuar con el régimen que nos había dado tantos beneficios y quienes querían un futuro inestable, lleno de incertidumbre y desigualdades. Por desgracia, triunfó la democracia, y con ella llegó la crisis.

Por ello, esta función social y cívica se hace más reconocible e identificable a través de la consecución de altos niveles empáticos (Molina y Egea, 2018; Sáiz, 2013).

Por otro lado, la propia percepción del alumnado sobre su capacidad para empatizar con sus personajes señala que 22 de ellos lo ha conseguido, mientras que el resto, 6 estudiantes, ha respondido de forma ambigua, por lo que el cuestionario también avala el cumplimiento de la función social y cívica, niveles que se aproximan a los expuestos por Sáiz (2013) y Molina y Egea (2018), y resultan algo superiores a los recabados por Guillén (2016), aunque en este caso puede deberse al hecho de que este último realiza una experiencia en segundo de ESO, y el factor edad puede haber sido determinante.

Para conocer si la experiencia ha sido útil desde un punto de vista formativo (objetivo específico número 3), se ha comprobado si los alumnos han sido capaces de aportar en sus narrativas conocimientos históricos vistos en clase y/o aprehendidos en su proceso de trabajo autónomo, si han sido capaces de dar una explicación correcta a los procesos históricos abarcados, si han cometido errores históricos significativos y, por último, si han trabajado correctamente con las fuentes. Los resultados indican que más de la mitad del alumnado ha cumplido con estos requisitos, lo que permite afirmar que la actividad ha sido útil para su formación histórica, aspecto que también ratifica las respuestas del cuestionario de conocimientos, y se encuentra en línea con estudios semejantes anteriormente citados (Sáiz, 2013; Pizarro y Cruz, 2014; Guillén, 2016; Molina y Egea, 2018).

En primer lugar, 22 de los alumnos aportan conocimientos históricos vistos en clase, entre los que predominan los referentes a la contextualización o a los episodios principales de la guerra. Es el caso del relato número 28, en el que se citan los sucesos de mayo de 1937 en Barcelona:

[28] Todo iba bien, hasta mayo de 1937 que las calles de Barcelona volvieron a llenarse de barricadas y cadáveres. En ese mes casi no fuimos al colegio porque había tiroteos continuamente, asesinatos de curas y burgueses, e incluso los propios republicanos se estaban enfrentando entre ellos. Había estallado una especie de "Guerra Civil" en Barcelona entre anarquistas y comunistas (POUM y CNT-FAlanarquistas se enfrentaron a los comunistas). Este conflicto fue ganado por los comunistas y estos eliminan el poder de la CNT.

Otro ejemplo lo encontramos en el relato número 9, que menciona la matanza de Badajoz:

[9] Durante el mes de agosto avanzamos por Extremadura, tomando ciudades como Mérida y Badajoz (otra ciudad donde los legionarios ejercieron, ante mis ojos, una brutal represión). 
Por otro lado, 27 de los alumnos han incorporado conocimientos aprendidos a través de la consulta de fuentes correspondientes a muy diversos temas, como por ejemplo los relacionados con la carestía de alimentos, presente en el relato número 16:

[27] A pesar de ser un plato tan poco atractivo la pasta de harina, bicarbonato y agua que sustituía al huevo y las mondas de la naranja que sustituían a la patata me parecían todo un manjar.

En cuanto a las correctas explicaciones de los procesos históricos, éstas se hallan en doce de los relatos, mientras que en siete de ellos se producen de forma escueta. Por el contrario, En cuanto a errores históricos significativos, éstos se hallan únicamente en tres de las narrativas, entre los que cabe destacar el presente en el relato número 12 :

[12] Mi padre lo defendía a capa y espada, pues como tenía entendido él también era socialista, siempre andaba gritando que él lucharía por la clase obrera si los bolcheviques se atrevían a sublevarse.

Incluímos igualmente el que aparece en el relato número 13:

[13] Tras la batalla volví a Vigo, mi lugar de procedimiento, donde me llamaron a formar filas (¿̇otra vez a filas?) (...) Tres días después el 1 de abril, durante la madrugada en la radio el general Francisco Franco anunció "no ha llegado la paz, sino la victoria", comunicando el fin de la guerra y el comienzo de una dura y larga dictadura".

Por otra parte, un examen de las fuentes consultadas por los alumnos, señala que en 20 de los 28 relatos se hallan fuentes válidas, mientras que en ocho son imprecisas o generalistas y en un caso nulas. En cuanto a este punto, hay que tener en cuenta que los alumnos no están acostumbrados a trabajar citando las fuentes que utilizan. También, que solamente se les pidió un apartado final de bibliografía/webgrafía en el que indicaran de dónde provenía la información, lo que ha hecho que algunos lo hayan señalado de forma muy generalista. Esta ausencia en el uso de fuentes se hizo aún más destacable en el cuestionario de conocimientos: ni uno solo de los participantes mencionó fuentes históricas en sus respuestas, denotando, una vez más, la gran falla existente entre la potencialidad de las fuentes históricas como herramienta para la enseñanza de la historia (Chillón y Friera, 1998; Prats y Santacana, 2001), y su uso real en las aulas.

Por último, centrándonos en las posibilidades de mejora de la actividad, 27 de los 29 estudiantes consideraron que el material entregado había sido útil aunque, al mismo tiempo, 10 de los 29 alumnos señalaron que había sido excesivo. Por otro lado, solo 5 de ellos consideraban que le hubiera gustado contar con más herramientas e instrumentos de investigación. En cuanto a la amplia libertad brindada, uno de los comentarios sugería lo siguiente: "Me gustaría que el trabajo hubiese estado un poco más guiado, es decir, con unos límites más marcados". Como estrategias de mejora, a 24 de los 29 alumnos le hubiera gustado compartir la experiencia de su personaje con las del resto de compañeros a través de actividades alternativas como entrevistas, juegos de preguntas, recreaciones, etc. A colación de esto, algunos se referían en los siguientes términos: "Que hubiéramos interactuado en la clase como nuestros personajes" o "Compartir los relatos en clase podía haber resultado útil". Finalmente, ante la cuestión de si sería una buena idea trazar todo un curso desarrollando la vida de un personaje ficticio para comprender la Historia de una manera más cercana, 21 de los alumnos apostaron por ello, frente 
a la sólida resistencia de los ocho restantes que se opusieron a esta opción. Todos estos datos apuntan a que esta actividad empática aún podría tener más recorrido teniendo en cuenta estas nuevas perspectivas.

Todo ello, no obstante, sí que ha servido para dejar entrever las diferencias abismales entre dos formas de entender el proceso de enseñanza-aprendizaje, dos modelos contrapuestos que pugnan desde el propio nacimiento de la asignatura de Historia, y a cuyo debate este proyecto quiere aportar, sin embargo, la validez de esta experiencia.

Porque, a pesar de las limitaciones, los resultados de este estudio de caso no han sido desfavorables, logrando alcanzar un nivel alto de empatía histórica contextualizada en 7 de los 29 alumnos que participaron en la experiencia, y un nivel medio en 14 de los mismos, lo que significa que 21 de los 29 estudiantes lograron empatizar mínimamente con su personaje.

\section{Reflexiones finales}

A partir de fundamentos teóricos sobre el pensamiento histórico como los presentados por autores como Lee y Ashby (2001), Foster (2001), Seixas (2011) y Seixas y Morton (2013), y de experiencias desarrolladas recientemente en España centradas en el análisis de la perspectiva y la empatía histórica como las de Pizarro y Cruz (2014), Guillén (2016), Calderón y Arias (2017), Miguel-Revilla y Sánchez (2018b) y Molina y Egea (2018), este proyecto, que bebe de dichos estudios, se propuso desarrollar un estudio de caso centrado en el desarrollo de la empatía histórica en $2 .^{\circ}$ de Bachillerato. Los objetivos giraban en torno a evaluar la función social y cívica de iniciativas relacionadas con el pensamiento histórico, su capacidad de motor motivacional en los alumnos, su utilidad desde un punto de vista formativo y sus repercusiones académicas en el sistema actual, así como la manifestación de aquellos aspectos de mejora.

Antes del diseño de la investigación, éramos conscientes de los problemas a los que nos enfrentábamos: el hecho de trabajar en $2 .^{\circ}$ curso de Bachillerato, si bien nos permitía plantear el estudio con un alumnado al que se suponía un alto nivel de conocimientos históricos, también nos hacía conocedores del enorme peso que tenía para estos las pruebas de acceso a la universidad (que condiciona altamente la dinámica habitual de las clases), y del hándicap que supone plantear a unos alumnos totalmente habituados a un modelo de trabajo y de evaluación de conocimientos muy centrado en la memorización, una nueva metodología de aprendizaje de la historia.

Con todo, y para intentar obtener la mayor cantidad posible de datos sobre la validez de la iniciativa, se hizo uso de una amplia gama de herramientas de recogida de datos que nos permitían, además de conocer el nivel de adquisición de la variable empatía histórica, comprobar también la repercusión en el rendimiento académico de los alumnos en contextos en los que se varía sustancialmente la dinámica de trabajo en el aula de Historia.

En este sentido, se observa un relativamente bajo nivel de adquisición de la competencia empática, que en este caso ha sido obtenido por buena parte del alumnado: solo siete de los 29 alumnos analizados alcanzaron un nivel alto de empatía histórica contextualizada, e incluso dos de ellos, que generalmente obtenían buenas calificaciones en la asignatura, suspendieron la prueba. Esto denota la enorme influencia que, en estos cursos, mantienen los modelos tradicionales 
de enseñanza de la historia, centrados fundamentalmente en la adaptación exclusiva a un modelo didáctico en el que predominan los conceptos de primer de orden, los contenidos cerrados y los exámenes memorísticos de preparación para la EBAU, dando lugar a la consecuente ausencia de experiencia en las competencias histórico, con las consecuencias cívicas que esto conlleva.

A la luz de estos datos, gran parte del alumnado sin embargo empeora sus logros académicos tras la estrategia empática. Esto puede deberse, por un lado, a que los alumnos no están acostumbrados a trabajar con este modelo de aprendizaje $y$, por otro, a que están más adaptados al modelo memorístico tradicional, lo que refleja el claro predominio de las técnicas tradicionales y la ausencia casi total de elementos de pensamiento histórico en las aulas. Por ello, estos resultados, si arrojan alguna certeza, es la existencia de una diferencia abismal entre dos formas de entender la enseñanza y el aprendizaje, concretamente en este caso, entre realizar un examen de tipo memorístico y llevar a cabo una actividad que implica procesos cognitivos y recursos propios del historiador.

Por último, en cuanto a las posibilidades de mejorar esta experiencia, existe un gran consenso entre los alumnos ( 27 de los 29 que realizaron el cuestionario de opinión) en la preferencia de realizar este ejercicio en cursos anteriores y su rechazo a realizarlo en $2 .^{\circ}$ de Bachillerato. A este respecto cabría señalar algunas de las sugerencias de los propios alumnos: "Sería interesante aplicar este trabajo a $4 .^{\circ}$ de la ESO, donde hay menos carga académica y la $2 .^{\circ}$ Guerra Mundial da más juego" y "Esta actividad la recomendaría para alumnado de $4 .^{\circ}$ de la ESO $\circ 1 .^{\circ}$ de Bachiller, pero no para $22^{\circ}$ de Bachiller". En este sentido, el peso que tiene para estos alumnos la prueba de acceso a la universidad (PAU o EBAU) es palpable, y es una de las posibles causas de que buena parte de las experiencias didácticas centradas en el desarrollo de la empatía histórica, como las desarrolladas por Cruz y Pizarro (2014) o Guillén (2016), se hayan realizado en cursos previos e incluso en niveles educativos inferiores (caso de Calderón y Arias, 2017).

En definitiva, este estudio ha servido de elemento motivador que ha movilizado la construcción activa del conocimiento histórico por parte del alumnado, cumpliendo asimismo la función social y cívica de la Historia. Todo ello a partir de una iniciativa que, además, ha dejado en los alumnos las huellas de la importancia de la contextualización, la perspectiva histórica, la dificultad de viajar al pasado y la comprensión de los motivos e intenciones de la otredad.

\section{Bibliografía}

Almansa, R. M. (2018). La empatía como método humanístico de docencia de la Historia: sugerencias didácticas en un panorama de desvalorización de los estudios históricos. Enseñanza de las Ciencias Sociales, 17, 87-98. Recuperado de: https://www.raco.cat/index.php/EnsenanzaCS/article/view/343303/434421

Altamira, R. (1997). La enseñanza de la Historia. Madrid: Akal.

Berti, A. E., Baldin, I. y Toneatti, L. (2009). Empathy in history. Understanding a past institution (ordeal) in children and young adults when description and rationale are provided. Contemporary Educational Psychology, 34, 278-288. Recuperado de: https://www.sciencedirect.com/science/article/pii/S0361476X09000174

Cairns, J. (1989). Some Reflections on Empathy in History. Historical Association, 55, 13-18. 
Calderón, P., y Arias, L. (2017). El desembarco de Colón en San Salvador. Análisis de las narraciones de alumnado español de 10-11 años en términos de perspectiva histórica. REIRE Revista d'Innovació i Recerca en Educació, 10(2), 34-51. doi: 10.1344/reire2017.10.217702

Carretero, M. (2007). Documentos de identidad. Contradicción y sentido de la enseñanza de la historia. Barcelona: Paidós.

Carretero, M., Rosa, A. y González, M. F. (2006). Enseñar historia en tiempos de memoria. En M. Carretero, A. Rosa y M. F. González (comp.), Enseñanza de la historia y memoria colectiva. Buenos Aires: Editorial Paidós.

Chillón J. L. y Friera, F. (1998). Dramatización y empatía en la enseñanza: el milenario de la donación del valle de Sariego al monasterio de San Pelayo (Asturias). Un ejemplo de utilización de textos y uso del lenguaje. Iber, 15, 114-121.

Dickinson, A. K., y Lee, P. (1978). Understanding and Research. En A. Dickinson y P. Lee (eds.), History Teaching and Historical Understanding (pp. 95-120). Londres: Heinemann Educational Books.

Domínguez, J. (2015). Pensamiento histórico y evaluación de competencias. Barcelona: Graó.

Éthier, M., Demers, S. y Lefrançois, D. (2010). Las investigaciones en didáctica sobre el desarrollo del pensamiento histórico en la enseñanza primaria. Enseñanza de las Ciencias Sociales, 9, 61-73. Recuperado de: https://www.researchgate.net/publication/254489712

Feliu, M. y Hernández, F. X. (2013). 12 ideas clave. Enseñar y aprender historia. Barcelona: Graó.

Foster, S. T. (2001). Historical Empathy in Theory and Practice: Some Final Thoughts. En O. L. Davis, E. A. Yeager y S. J. Foster (eds.), Historical empathy and perspective taking in the social studies. Oxford: Rowman \& Littlefield.

Gómez, C. J. y Molina, S. (2017). Narrativas nacionales y pensamiento histórico en los libros de texto de Educación Secundaria de España y Francia. Análisis a partir del tratamiento de los contenidos de la Edad Moderna. Vínculos de Historia, 6, 206-229. doi: $10.18239 / \mathrm{vdh} . \mathrm{v} 0 \mathrm{ib} .276$

Gómez, C. J., Ortuño, J. y Molina, S. (2014). Aprender a pensar históricamente. Retos para la historia en el siglo XXI. Revista Tempo e Argumento, 6(11), 5-27. Recuperado de: http://periodicos.udesc.br/index.php/tempo/article/viewFile/2175180306112014005/ $\underline{3052}$

González, N., Enríquez, R., Pagès, J. y Santisteban, A. (2009). El aprendizaje de la empatía histórica (eh) en educación secundaria. Análisis y proyecciones de una investigación sobre la enseñanza y el aprendizaje del conflicto y la convivencia en la Edad Media. En AAVV (ed.), La educación de la ciudadanía y la formación del profesorado. Un proyecto educativo para la "estrategia de Lisboa". Bolonia: Pàtron Editore.

Guillén, M. (2016). Un viaje al siglo XVI a partir de los casos de un corsario y un bandolero. Una experiencia de empatía histórica en Secundaria. Clio. History and History teaching, 42. Recuperado de: http://clio.rediris.es/n42/articulos/guillen2016.pdf

Harris, R. y Foreman-Peck, L. (2014). Stepping into other people's shoes': teaching and assessing empathy in the Secondary History Curriculum. International Journal of Historical Learning, Teaching and Research, 4(2), 1-14. doi: 10.18546/HERJ.04.2.11 
Lee, P. y Ashby, R. (2001). Empathy, perspective taking and rational understanding. En O. L. Davis, E. A. Yeager y S. J. Foster (eds.), Historical empathy and perspective taking in the social studies. Oxford: Rowman \& Littlefield.

Lee, P. y Shemilt, D. (2011). The concept that dares not speak its name: Should empathy come out of the closet? Teaching History, 143, 39-48.

López, R. (2010). Nacionalismos y europeísmos en los libros de texto: Identificación e identidad nacional. Clío \& Asociados, 14, 9-33. doi: 10.14409/cya.v1i14.1673

Martín, D. (2010). La empatía en la enseñanza de la historia. A la búsqueda de la empatía en un aula de los Andes. Iber. Didáctica de las Ciencias Sociales, Geografía e Historia, 64, 102110.

Merchán, J. y Duarte, O. (2014). Los grupos de innovación en la enseñanza de la Historia de España en Bachillerato: innovación, cambio y continuidad. En N. Martínez Valcárcel (coord.), La historia de España en los recuerdos escolares: análisis, interpretación y poder de cambio de los testimonios de profesores y alumnos (pp. 53-74). Valencia: Nau Libres.

Miguel-Revilla, D. y Sánchez, M. (2018a). Conciencia histórica y memoria colectiva: marcos de análisis para la educación histórica. Revista de estudios sociales, 65, 113-125. doi: $10.7440 /$ res65.2018.10

Miguel-Revilla, D. y Sánchez, M. (2018b). Modelos de conciencia histórica en el alumnado de Educación Secundaria: tradición, simbología y contextualización en torno a los restos del franquismo. Panta Rei. Revista Digital de Ciencia y Didáctica de la Historia, 119-142. doi: $10.6018 /$ pantarei/2018/6

Molina, S. Miralles, P., Deusdad, B. y Alfageme, M. B. (2017). Enseñanza de la historia, creación de identidades y prácticas docentes. Profesorado: revista de curriculum y formación del profesorado, 21(2), 331-354. Recuperado de: https://recyt.fecyt.es/index.php/profesorado/article/view/59463/36175

Molina, S. y Ortuño, J. (2019). Concepciones del profesorado sobre el papel de la enseñanza de la historia en la formación de identidades colectivas. En A. Delgado y A. Rivera (eds.), ¿̇Qué saben de su historia nuestros jóvenes? Enseñanza de la historia e identidad nacional (pp. 4355). Granada: Comares.

Molina, S. y Egea, J. (2018). Evaluar la adquisición de las competencias históricas en Secundaria: un estudio de caso centrado en la empatía histórica. Ensayos, Revista de la Facultad de Educación de Albacete, 33(1), 1-22. doi: 10.18239/ensayos.v33i1.1737

Molpeceres, A. (2006). Los ecos del pasado en el presente. Lo que los alumnos saben y perciben de la guerra civil. Aula de innovación educativa, 157, 27-31.

Pizarro, F. y Cruz, P. (2014). Empatía en clase de Historia: los alumnos serán soldados de la Primera Guerra Mundial. Clio. History and History teaching, 40. Recuperado de: http://clio.rediris.es/n40/articulos/LosalumnossoldadosdelaPrimeraGuerraMundial.pdf

Prats, J. y Santacana, J. (2001). Principios para la enseñanza de la Historia. En J. Prats, Recursos didácticos. Enseñar Historia: Notas para una Didáctica Renovadora. Mérida: Junta de Extremadura.

Prats, J. y Santacana, J. (2011). ¿PPor qué y para qué enseñar historia? En AAVV (ed.), Enseñanza y aprendizaje de la historia en la educación básica (pp. 18-64). México DF: UNAM. 
Rodríguez, C. y López, C. (2009). Estudios cognitivos sobre el conocimiento histórico: aportaciones para la enseñanza y alfabetización histórica. Enseñanza de las Ciencias Sociales, 8, 75-89. Recuperado de: https://www.raco.cat/index.php/EnsenanzaCS/article/view/184396

Sáiz, J. (2013). Empatía histórica, historia social e identidades: pensar históricamente la conquista cristiana de la Valencia musulmana con estudiantes de $2 .^{\circ}$ de ESO. Clío. History and History Teaching, 39. Recuperado de: http://clio.rediris.es/n39/articulos/historiasocial/saiz.pdf

Salazar, R. A. (2016). La construcción del discurso histórico en estudiantes de ESO: El aula como laboratorio [Tesis doctoral]. Barcelona: Facultad de Educación. Recuperado de http://hdl.handle.net/10803/390947

Sallés, N. y Santacana, J. (2016). Los grupos de innovación educativa en la Enseñanza de la Historia en España. Educatio siglo XXI, 34(2), 145-166. doi: 10.6018/i/263851

Santisteban, A. (2010). La formación de competencias de pensamiento histórico. Clío \& Asociados, 14, 34-56. Recuperado de: http://www.memoria.fahce.unlp.edu.ar/art revistas/pr.4019/pr.4019.pdf

School Council History 13-16 Project (1976). A New Look at History. Edinburgh: Homes McDougall.

Seixas, P. (201 1). Assessment of historical thinking. En P. Clark (ed.), New possibilities for the past, shaping history education in Canada. Vancouver: UBC Press.

Seixas, P. y Morton, T. (2013). The Big Six Historical Thinking Concepts. Toronto: Nelson College.

Shemilt, D. (1984). Beauty and the Philosopher: Empathy in History and Classroom. En A. K. Dickinson, P. J. Lee y P. J. Rogers (coords.), Learning History (pp. 39-84). Londres: Heinemann Educational Books.

Tribó, G. (2005). Enseñar a pensar históricamente. Los archivos y las fuentes documentales en la enseñanza de la historia. Barcelona: ICE/HORSORI.

Yilmaz, K. (2007). Historical empathy and its implications for classroom practices in schools. The History Teacher, 40(3), 331-337. Recuperado de: https://www.researchgate.net/publication/215643395 Historical Empathy and Its Impl ications for Classroom Practices in Schools 


\title{
Anexo I
}

\section{Perfiles biográficos asignados al alumnado y numeración utilizada para la identificación del relato}

\author{
Relato Fuente utilizada Descripción (perfil introductorio)
}

3 http://bancmemorial.genc at.cat/

4

http://bancmemorial.genc at.cat/

https://mujerymemoria.or $\mathrm{g} /$ web

http://bancmemorial.genc at.cat/

http://bancmemorial.genc at.cat/

http://platea.pntic.mec.es / anilo/abuelos/marco3. htm

https://www.elmundo.es/ especiales/espana/guerr a-civil/relatos/

1 https://www.youtube.com $/$ watch? $v=$ ruUJ-tcUBnM

https://www.youtube.com $/$ watch?v=r4dqcMgSH64

https://www.galiciamaxic a.eu/

http://bancmemorial.genc at.cat/

http://www.todoslosnomb res.org

https://www.plusesmas.co $\mathrm{m} /$ nostalgia/biografias/v ictoria_kent/

http://aunamendi.euskoikaskuntza.eus/eu/
Josep Busquets Subirats. Tortosa, 1920. De familia trabajadora. Afiliado al Partido Radical Socialista.

Onelia Castriz Muñoz. Avilés, 1927. Hijastra de un diputado provincial socialista. Sin especiales convicciones políticas.

Carmen Perea Sánchez, Burgos, 1925. De familia humilde con ideas tradicionalistas. Afín a Falange.

Purificación Gallego Prieto, Madrid, 1913. De familia humilde. Afiliada al Partido Socialista.

Pedro Alonso Pérez. Madrid, 1922. Hijo de un fundador de la Federación Anarquista Ibérica. Afiliado al Partido Comunista.

Bernardino Hernández, Sevilla 1919 en Sevilla. De familia acomodada, movilizado por el bando nacional. Sin especiales convicciones políticas.

Concha Martínez, Barcelona 1918. Hija de un obrero afiliado a CNT. Afiliada a las Juventudes Socialistas Unificadas.

Josefa Carmín, Gijón 1918. De familia humilde comprometida con las luchas de los mineros. Afiliada a las Juventudes Socialistas Unificadas.

Catalina Sánchez, Rus (Jaén), 1918. De familia humilde de una zona rural, afín al Partido Socialista. Sin especiales convicciones políticas.

José Antonio Ramírez Castillo, Salgueiro, 1917. De familia humilde. Movilizado por el Bando Nacional. Sin especiales convicciones políticas.

Francisco Jiménez Alcalde. El Entrego (Asturias), 1919. De familia minera. Afiliado a las Juventudes Socialistas Unificadas.

Pedro Salazar Perea. Bujalance (Córdoba), 1918. De familia de jornaleros de ideas anarquistas. Tras la guerra se une al maquis.

María Siano González, Málaga, 1898. De familia acomodada. Titulada universitaria. Diputada por el Partido Radical Socialista.

Rosa Martínez Pastor. Madrid, 1902. De familia militar tradicionalista. Integrante de Acción Católica y Comunión Tradicionalista. 
Inspirado en el resto de perfiles

http://bancmemorial.genc at.cat/

https://www.elmundo.es/ especiales/espana/guerr a-civil/relatos/

Inspirado en el resto de perfiles

http://puertoreal.cnt.es/

http://www.fpabloiglesia s.es/

http://bancmemorial.genc at.cat/

http://bancmemorial.genc at.cat/

http://www.terrynorm.ic2 4.net/spanish $\% 20$ civil\%2 Owar.htm

Inspirado en el resto de perfiles

http://bancmemorial.genc at.cat/

Inspirado en el resto de perfiles

https://fnff.es/memoriahistorica/

Inspirado en el resto de perfiles
Josefa Martínez Pérez. Mula, (Murcia), 1928. De familia de labradores pobres. Analfabeta. Sin especiales convicciones políticas.

Carme Casas Godessar. Sotonera (Huesca), 1921. Hija de un maestro de escuela republicano. Sin especiales convicciones políticas.

Pedro José Pérez Ruiz. Meruelo (Cantabria),1918. Fundador de Falange Española en su localidad y secretario de las Juventudes Católicas.

María Sandoval Fernández. Almagro (Ciudad Real), 1920. De familia humilde. Analfabeta. Sin especiales convicciones políticas.

Concepción Martínez Fuster. Barcelona, 1915. De familia de clase media. Titulada universitaria de ideas anarquistas.

Celia Martínez Prieto. Madrid, 1915. Hija de un ferretero. Miembro del sindicato de la UGT, combatiente.

Ana Soler. Darnius (Girona), 1922. Hija de panaderos afines a los partidos de izquierda. Sin especiales convicciones políticas.

María del Carmen Torregrosa. Barcelona, 1924. De familia humilde de ideas anarquistas. Sin especiales convicciones políticas.

James Elliot. Ammanford (Gales), 1908. De familia minera. Afiliado al Partido Comunista. Miembro de las Brigadas Internacionales.

Encarnación López. Archena (Murcia), 1926. De familia de jornaleros. Prácticamente analfabeta. Sin especiales convicciones políticas.

Ana Busquets. Esplugues (Barcelona), 1923. De familia humilde. Sin especiales convicciones políticas.

Alicia Valero. Archena (Murcia), 1917. Hija de braceros agrícolas. Prácticamente analfabeta. Sin especiales convicciones políticas.

José Ruíz Martínez. La Carolina (Jáen), 1919. De familia acomodada católica. Afiliado a Falange.

Francisco Zafra Nortes. Burgos, 1917. De familia humilde católica y tradicionalista. Afín al bando sublevado. 


\section{Panta Rei}

PANTA REl es una revista digital de investigación orientada a la Historia y la Didáctica de la Historia. Su principal objetivo es la transmisión del conocimiento científico, dando una oportunidad también a los jóvenes investigadores que quieren abrirse camino en el estudio de las ciencias humanas y sociales. Se compone de estudios originales relacionados con la disciplina histórica así como su didáctica y difusión. Las diferentes secciones que componen la revista son: artículos de investigación, entrevistas a profesionales, recensiones de monografías de actualidad y crónicas de congresos o eventos científicos relevantes.

Todos los artículos publicados son objeto de un proceso de revisión a cargo de un mínimo de dos evaluadores, que se consideran expertos en el ámbito temático del artículo propuesto. Nuestro deseo es poder ofrecer unos contenidos rigurosos, de calidad y de interés.

El CEPOAT (Centro de Estudios del Próximo Oriente y la Antigüedad Tardía de la Universidad de Murcia) es la institución encargada de la coordinación y gestión de la revista, desde donde anualmente se lanzará la convocatoria para aquellos que estén interesados en publicar sus trabajos, siempre relacionados con la Historia y la Didáctica de la Historia.

PANTA REI is a digital journal focused on History and Teaching History. Its main objective is the transmission of scientific knowledge by giving also an opportunity to young researchers who want to make their way in the study of human and social sciences. It is composed by original studies related to History, as well as its didactics and promotion. The different sections of this journal are: research articles, interviews to professionals, recensions on monographs about current issues and reports about congresses or relevant scientific events.

All the articles published are subject to a revision process carried out by a minimum of two reviewers who are considered to be experts in the field of the article proposed. Our wish is to offer rigorous contents with quality and being of interest to the reader.

CEPOAT (Centre of Studies of the Middle East and Late Antiquity of the University of Murcia) is the institution in charge of the coordination and management of this journal. This is the centre from where the call for papers will be launched annually for all the people interested in publishing their papers, always related to History and Teaching History. 


\section{Normas de publicación}

El autor se compromete a enviar trabajos originales, que no se encuentren publicados en otras revistas ni en otros idiomas. Así mismo, el mismo artículo no podrá ser presentado en otras revistas mientras dure el proceso de evaluación.

\section{Envío y presentación de originales}

Las normas de edición y forma de envío de artículos a la revista se pueden consultar en https://revistas.um.es/pantarei/

Para la redacción de los trabajos se tendrá en cuenta el Manual de la American Psychological Association, en su $7 .^{a}$ edición. La extensión máxima de los trabajos será de 25 páginas. La revista acepta originales escritos en español o inglés.

\section{Proceso de valoración y evaluación}

Una vez recibidos los trabajos, la Revista realizará una primera valoración. Si el trabajo enviado se ajusta a las normas de presentación propuestas, la temática es coincidente con la línea editorial de la revista y posee la calidad científica necesaria, será remitido al consejo asesor para una primera evaluación. Si no es así en este primer paso se puede rechazar directamente los documentos que incumplan claramente la línea editorial.

Será el Consejo Asesor quien indique a la revista la originalidad, relevancia, estructura, redacción, aparato bibliográfico, etc. del trabajo enviado y, para ello, se designará a dos revisores expertos externos que evaluarán cada uno de los trabajos, que pueden formar parte (o no) de este Consejo Asesor. La selección de los revisores se ajustará a la temática y características metodológicas del trabajo. El nombre y filiación de los autores serán eliminados del trabajo para su revisión, así como los revisores actuarán de manera anónima y confidencial.

Los revisores deberán rellenar un informe de evaluación que centrará su atención en aspectos tales como características formales, originalidad y novedad de los trabajos, relevancia de las propuestas y los resultados, calidad metodológica y validez científica.

Una vez terminado el proceso se decidirá la aceptación o no de los mismos y su publicación en el número que sea pertinente, así como las modificaciones susceptibles de ser realizadas para su final publicación. Dicha notificación se enviará únicamente por correo electrónico, en un plazo máximo de seis meses. 


\section{Publishing rules}

The author is committed to submit original papers not having been published in other reviews or in other languages. In this way, it is not allowed for the same paper to be presented in other reviews during the evaluation process.

\section{Submission and presentation of originals}

The editing rules and the guidelines for the submission of papers can be consulted at https://revistas.um.es/pantarei/

The seventh edition of the Manual of the American Psychological Association will be taken into account for the writing of the papers. The length of the submitted papers will not exceed the 25 pages. The journal accepts originals written in Spanish or English.

\section{Examination and assessment process}

The Journal will submit the papers to a first examination once received. If the paper follows the presentation guidelines, the subject agrees with the editorial line of this journal, and possess the scientific quality required, it will be sent to the advisory council for a first assessment. If not, the documents which clearly fail to complete the editorial line may be rejected straightaway in this first step.

The Advisory Council will indicate the originality, relevance, structure, writing, bibliography, etc. of the text to the journal; for this purpose, two outside experts will be designated to review the papers; these experts can be (or not) part of this Advisory Council. The selection of the experts will adjust to the subject and methodological characteristics of the paper. Name and affiliation of the author will be eliminated from the text for its review, in this way experts will act anonymously and confidentially.

The experts will fill out an assessment report which will focus on aspects such as formal characteristics, originality and novelty of the papers, relevance and results of the proposal, methodological quality and scientific validity.

Once the process is finished, the acceptance or not of the papers and its publication in the corresponding edition will be decided, as well as the modifications that may be done for its final publication. This notification will be sent by email within 6 months maximum. 


\section{cepoAt edit.um}

